\title{
Giving Up the Enkratic Principle
}

\author{
(forthcoming in Logos and Episteme)
}

\begin{abstract}
The Enkratic Principle enjoys something of a protected status as a requirement of rationality. I argue that this status is undeserved, at least in the epistemic domain. Compliance with the principle should not be thought of as a requirement of epistemic rationality, but rather as defeasible indication of epistemic blamelessness. To show this, I present the Puzzle of Inconsistent Requirements, and argue that the best way to solve this puzzle is to distinguish two kinds of epistemic evaluation - requirement and appraisal. This allows us to solve the puzzle while accommodating traditional motivations for thinking of the Enkratic Principle as a requirement of rationality.
\end{abstract}

Keywords: Enkratic Principle; coherence; evidence; rationality

\section{The Enkratic Principle}

The Enkratic Principle demands coherence. In the epistemic domain, it demands coherence between the agent's beliefs about which epistemic attitudes she ought to have, and her firstorder $^{1}$ epistemic attitudes ${ }^{2}$. According to the orthodox view, the Enkratic Principle is a

\footnotetext{
1 'First-order' is not the ideal term. By 'first-order' I mean epistemic attitudes whose content does not concern what we ought, rationally, to believe.

${ }^{2}$ These could include believing, disbelieving, refraining from believing, suspending, or having a particular credence in a proposition.
} 
requirement of epistemic rationality ${ }^{3}$. Reading $\mathrm{O}$ as "rationally required", $\Phi$ as representing a doxastic attitude, and B as representing belief, the principle can be stated as follows:

$$
\text { Enkratic Principle: } \mathrm{O}(\mathrm{BO} \Phi \rightarrow \Phi)
$$

The Enkratic Principle says that rationality requires either having the attitudes you believe you ought to have, or giving up the belief that you ought to have those attitudes. It prohibits combinations of attitudes that include the belief that believing $\mathrm{P}$ is required, but not the belief P.

It is not hard to see why the Enkratic Principle has been thought to be a requirement of epistemic rationality - attitudinal coherence can seem definitional of what rationality demands ${ }^{4}$. Nevertheless, rejecting this orthodoxy is the best way to solve a stubborn puzzle that arises from the possibility of misleading evidence about what rationality requires - the Puzzle of Inconsistent Requirements. I argue that distinguishing between two distinct kinds of epistemic evaluation - evaluations of whether attitudes meet the requirements of rationality, and evaluations of whether epistemic praise or blame is deserved - offers the best way to solve the puzzle. Rather than thinking of the Enkratic Principle as a requirement of rationality, we should view the attitudinal coherence it demands as defeasible indication that the agent is epistemically blameless. The following section describes the Puzzle of Inconsistent Requirements. Section 3 diagnoses the puzzle as arising from a conflation of two distinct kinds of evaluation sometimes associated with evaluations of rationality. Section 4 shows how distinguishing these allows us to solve the puzzle. Section 5 defends the proposed strategy as

\footnotetext{
${ }^{3}$ It is also typically thought to be a requirement of practical rationality, but here I am concerned only with the epistemic version.

${ }^{4}$ See, for example, John Broome, Rationality Through Reasoning (Wiley-Blackwell, 2013); Richard Feldman, "Respecting the Evidence", Philosophical Perpsectives 19, No. 1 (2005), Sophie Horowitz, "Epistemic Akrasia", Noûs 48 (2014); Niko Kolodny, "Why Be Rational?", Mind 114 (2005), Clayton Littlejohn "Stop Making Sense? On a Puzzle about Rationality", Philosophy and Phenomenological Research, 93 (2015), Michael Titelbaum, "Rationality's Fixed Point (Or: In Defense of Right Reason)" in Oxford Studies in Epistemology, Vol. 5 eds. Tamar Szabó Gendler and John Hawthorne (Oxford: Oxford University Press: 2015), and Jonathan Way, "The Symmetry of Rational Requirements", Philosophical Studies 155 (2011).
} 
the best solution available - it is the least theoretically costly of the available solutions, and it allows us to accommodate traditional motivations for the orthodox view.

\section{The Puzzle of Inconsistent Requirements}

Suppose that you are required to $\Phi$, in virtue of some set of normative requirements. Then, suppose that you have some misleading evidence that in fact, you are required to refrain from $\Phi$-ing. Are you required to $\Phi$ ? Or are you required to refrain from $\Phi$-ing, as your evidence indicates? On the one hand, you seem to be required to $\Phi$, since this is what complying with the normative requirements demands. However, you also seem to be required to refrain from $\Phi$-ing. This is what your evidence indicates you ought to do, and the Enkratic Principle requires coherence between your higher-order judgments about what you ought to do. You cannot rationally give up the higher-order judgment because it is supported by your evidence, so you appear to be subject to conflicting requirements to $\Phi$ and also to refrain from $\Phi$-ing. This generates a puzzle. The puzzle is particularly problematic when the normative requirements involved are the requirements of epistemic rationality. Here is an example:

Logic 101. Suppose that rationality prohibits contradictory belief. Suppose also that it is your first day of university, and you are about to take your first philosophy class. You sign up for an introductory course in logic. Unluckily, your instructor is an overzealous advocate of dialetheism ${ }^{5}$. He believes that rationality sometimes requires inconsistent belief, particularly in matters concerning truth ${ }^{6}$, and he intends to set you on the right track by introducing

\footnotetext{
5 As developed by Graham Priest. See his "The Logic of Paradox", Journal of Philosophical Logic 8 (1985), "Contradiction, Belief and Rationality", Proceedings of the Aristotelian Society 86 (1985), Doubt Truth to Be a Liar (Oxford: Oxford University Press: 2005), and In Contradiction: A Study of the Transconsistent (Oxford: Oxford University Press, 2006).

${ }^{6}$ For example, "it seems to me that anyone weighing up the state of play concerning [truth], ought rationally to be inconsistent." (Priest, In Contradiction: A Study of the Transconsistent, 125).
} 
you to the best arguments in favour of this position. You study in depth all the best arguments for dialetheism, and by the end of the course you believe - on the basis of good but misleading evidence - that rationality sometimes requires contradictory belief. As you walk out of class you see some graffiti that is a version of the Liar Paradox ("The writing on this wall is false.").

You seem to be simultaneously required to believe and not believe a contradiction. The true requirements require you to refrain from believing contradictions. However, you have testimony and arguments indicating that in this case rationality requires you to believe a contradiction. Assuming that epistemic rationality requires you to believe what your evidence supports, you are required to believe that rationality requires you to believe the contradiction. You can comply with the Enkratic Principle by either believing the contradiction, or by giving up the belief that you are rationally required to believe a contradiction. However, your evidence supports the belief that you are rationally required to believe a contradiction; giving up the higher-order judgment would be to ignore this evidence. So, if you are to believe what your evidence supports, and comply with the Enkratic Principle, then you ought to believe the contradiction. Your unfortunate epistemic situation - the fact that you have been exposed to misleading arguments for a false philosophical view - does not change what rationality requires. If epistemic rationality really prohibits contradictory belief, then you are required to refrain from believing contradictions. The Puzzle of Inconsistent Requirements is that epistemic rationality appears to generate inconsistent requirements in cases such as this one. It appears to require you to both believe and not believe the contradiction. 
It is worth pointing out that generating the puzzle does not depend on the possibility of rationally doubting any particular principle of classical logic ${ }^{7}$. Here is another example ${ }^{8}$ :

Disagreement. Suppose that rationality requires you to remain steadfast in your beliefs when epistemic peers disagree with you. Then suppose you write a $\mathrm{PhD}$ on the epistemology of disagreement. You exert significant effort considering arguments bearing on whether one should conciliate or remain steadfast in the face of disagreement, reaching the conclusion that rationality requires conciliation in response to disagreement from epistemic peers ${ }^{9}$. One evening, while discussing politics, you assert $\mathrm{P}$ (in which you have a credence of 0.8 ). Your partner (who is your epistemic peer on this matter) disagrees with you.

Epistemic rationality requires you to remain steadfast. Nevertheless, your total evidence supports the view that rationality requires you to conciliate. By the Enkratic Principle, you ought to either reduce your credence in $\mathrm{P}$ or give up the belief that you ought to conciliate in response to peer disagreement. However, to give up the belief that you ought to conciliate would be to ignore your evidence, so you do not seem to be rationally permitted to take this option. Even so, the fact that your evidence supports a false philosophical view does not change

\footnotetext{
${ }^{7}$ Some have thought the irrationality of contradictions is too certain to be rationally doubted. Putnam argues that his minimal principle of contradiction ('not every statement is true and false') presupposes the possibility of debate, thought, and explanation (Hilary Putnam, "There is at least one a priori truth", Erkenntnis 13). Lewis declines to debate the matter because "the principles not in dispute are so very much less certain than noncontradiction itself that it matters little whether or not a successful defence of non-contradiction could be based on them" David Lewis "Letters to Priest and Beall" in The Law of Non-Contradiction eds. Graham Priest, J.C. Beall, and Bradley Armour-Garb (Oxford University Press, 2004, 176). The Puzzle of Inconsistent Requirements does not turn on these issues.

${ }^{8}$ The puzzle has also been motivated using requirements to (not) believe lottery propositions (Littlejohn, "Stop Making Sense? On a Puzzle about Rationality"); requirements governing perception, testimony, and Lewis' Principal Principle Darren Bradley, "Are There Indefeasible Epistemic Rules?", Philosophers' Imprint 19 (2019: 2); and external world scepticism (Feldman, "Respecting the Evidence").

${ }^{9}$ Perhaps you think that intellectual modesty is more important than avoiding theories that are self-undermining (in disagreement with Adam Elga, "How to Disagree about How to Disagree" in Disagreement eds. Richard Feldman and Ted Warfield, (Oxford University Press, 2007).
} 
what rationality requires of you; it does not change the fact that you ought to remain steadfast. Again, rationality appears to make conflicting demands of you: you are required to both reduce and not reduce your credence in $\mathrm{P}$.

The Puzzle of Inconsistent Requirements involves cases of apparent intra-domain conflict between normative requirements. It is thus importantly different from a similar, and more benign, puzzle involving inter-domain conflict between normative requirements, for example:

Lying. Suppose that morality requires that you act so as to protect the lives of innocents, in all situations - even if this would sometimes require you to lie. Suppose also that you have recently taken a course on ethics led by a professor who defends a somewhat extreme Kantian view on the moral permissibility of lying. According to this view, lying is morally wrong in all cases, even if by lying you could save a life. You are a good student - you do the reading, you follow the arguments you are presented with in class, and you come to believe that lying is morally impermissible in all cases. One day, an infamous axe murderer comes to your door, in pursuit of your friend Stefano, and asks you where he is. In fact, Stefano is hiding in your house. You know that you could easily save his life by lying to the murderer ${ }^{10}$.

Morality requires that you lie to protect Stefano. However, your total evidence supports the view that morality prohibits lying. In this instance, morality requires you to lie, but epistemic rationality seems to require you not to lie. This is much less worrying than the Puzzle of

\footnotetext{
${ }^{10}$ See Immanuel Kant, "On a Supposed Right to Lie from Philanthropy (1797)" in Practical Philosophy ed. Mary Gregor (Cambridge University Press, 1996). For a sympathetic approach to Kant's rigorism about lying, see Wolfgang Schwarz, "Kant's Refutation of Charitable Lies", Ethics, 81(1970) and Jacob Weinrib, "The Juridical Significance of Kant's 'Supposed Right to Lie."', Kantian Review 13 (2008). Many have attempted to save Kant from the commitment to prohibit lying in all cases, including: Christine Korsgaard, "The Right to Lie: Kant on Dealing with Evil", Philosophy and Public Affairs 15 (1986); Tamar Schapiro, "Kantian Rigorism and Mitigating Circumstances", Ethics, 117 (2006); and Allen Wood, Kantian Ethics. (Cambridge University Press, 2008, Ch. 14).
} 
Inconsistent Requirements; the observation that morality and epistemic rationality sometimes conflict is not, itself, surprising. To resolve inter-domain conflict, we need only decide which set of normative requirements to prioritise - those of morality or rationality. While this is not always a straightforward question ${ }^{11}$, we can answer it without overhauling our theories of the normative requirements of morality or rationality. The same cannot be said for the intradomain involved in Logic 101 and Disagreement. Unlike inter-domain conflict, intra-domain conflict implies that our current theories of normative requirements have internal inconsistencies demanding resolution.

The Puzzle of Inconsistent Requirements is also importantly different from puzzles involving misleading higher-order evidence ${ }^{12}$. Here is a typical example:

Medicine. You are a medical doctor who diagnoses patients and prescribes appropriate treatment. After diagnosing a particular patient's condition and prescribing certain medications, you are informed by a nurse that you have been awake for 36 hours. You diagnose a patient with Disease D, forming the belief <patient has D>. In fact, you are correct. However, you know that people are prone to making cognitive errors when sleep-deprived (perhaps you even know your own poor diagnostic track-record under such

\footnotetext{
${ }^{11}$ See Broome, Rationality Through Reasoning and "Normative Requirements", Ratio 12 (1999), as well as Elizabeth Harman, "The Irrelevance of Moral Uncertainty" in Oxford Studies in Metaethics, Vol. 10, ed. Russ Shafer-Landau (Oxford University Press, 2015) for discussion of this.

12 This similar but distinct puzzle is discussed in David Christensen, "Higher-Order Evidence", Philosophy and Phenomenological Research 81 (2010; Adam Elga, "The Puzzle of the Unmarked Clock and the New Rational Reflection Principle", Philosophical Studies 164 (2013), Horowitz, "Epistemic Akrasia", Maria Lasonen-Aarnio "Enkrasia or Evidentialism?", Philosophical Studies, 177 (2020), "Higher-order Evidence and the Limits of Defeat", Philosophy and Phenomenological Research (2014), Paulina Sliwa and Sophie Horowitz, "Respecting all the Evidence", Philosophical Studies 172 (2015); Brian Weatherson, Normative Externalism (Oxford: Oxford University Press, 2019), Timothy Williamson, "Improbable Knowing" in Evidentialism and its Discontents ed. Trent Dougherty (Oxford University Press, 2011); and Alex Worsnip, "The Conflict of Evidence and Coherence", Philosophy and Phenomenological Research 96 (2018). For a solution to that puzzle that, like this one, accepts the occasional rationality of level-incoherence, see Lasonen-Aarnio ("Enkrasia or Evidentialism?", "Higher-Order Evidence and the Limits of Defeat"), and Weatherson (Normative Externalism).
} 
circumstances), so you also believe <I ought not believe that patient has D>, because it is not supported by your evidence ${ }^{13}$.

Your evidence appears to support both of the following beliefs ${ }^{14}$ :

$<$ The patient has disease D>

$<$ My evidence does not support that the patient has disease D>

The problem is that you have good evidence for $\mathrm{P}$, but misleading evidence about your current ability to assess the evidence for P. If these beliefs are supported by your total evidence, then believing what your evidence supports means believing both. However, this seems to violate the Enkratic Principle. Misleading higher-order evidence puzzles rely on two substantive claims about epistemic rationality: that it is possible for one's total evidence to support such combinations $^{15}$, and that what epistemic rationality requires is completely determined by what one's total evidence supports. Although the Puzzle of Inconsistent Requirements can be stated in terms of misleading evidence about what epistemic rationality requires, it is independent of this and other specific claims about what epistemic rationality requires. The intra-domain conflict arises not between first- and higher-order evidence, but between what the evidence supports and what the true requirements require. All that is needed to generate our puzzle is at least one requirement of rationality (e.g. Non-Contradiction, Conciliation), a commitment to the Enkratic Principle, and some misleading evidence sufficient to support a false belief about

\footnotetext{
13 Christensen ("Higher Order Evidence", 186) and Weatherson (Normative Externalism, 130) discuss this example.

${ }^{14}$ At least, according to Christensen ("Higher Order Evidence"), Lasonen-Aarnio ("Enkrasia or Evidentialism?", "Higher-order Evidence and the Limits of Defeat"), and Weatherson (Normative Externalism).

${ }^{15}$ For some disagreement, see Jessica Brown (Fallibilism: Evidence and Knowledge (Oxford University Press, 2018, Ch. 5, 6)), Horowitz, ("Epistemic Akrasia"), and Sliwa \& Horowitz ("Respecting All the Evidence"). This also turns on the question of whether higher-order evidence 'screens off' first-order evidence. For discussion, see Richard Feldman ("Reasonable Religious Disagreements" in L. Antony (Ed.), Philosophers Without Gods: Meditations on Atheism and the Secular Life ed. Louise Antony (Oxford University Press, 2007)), Brandon Fitelson ("Evidence of evidence is not (necessarily) evidence", Analysis 72 (2012)), William Roche (Is Evidence of Evidence Evidence? Screening-Off vs. No-Defeaters", Episteme, 15 (2018), William Roche and Tomoji Shogenji, "Confirmation, transitivity, and Moore: the Screening-Off Approach", Philosophical Studies 3 (2013)).
} 
what rationality requires. This makes possible situations in which one is rationally required (by the misleading evidence) to believe a false claim about what rationality requires, and also rationally required (by the true requirements of rationality) to adopt a first-order attitude that conflicts with that false belief.

The Puzzle of Inconsistent Requirements depends on the following three plausible claims, and can be solved by giving up at least one of them:

Externalism: There are facts about what rationality requires ("the rational requirements"), and these facts are independent of agents' epistemic perspectives $^{16}$.

Support: If $\mathrm{S}$ 's total evidence supports believing $\mathrm{P}$, then $\mathrm{S}$ is rationally required to believe $\mathrm{P}^{17}$.

Enkratic Principle: Rationality requires that the agent either has the attitudes she believes she ought to have, or gives up the belief that she ought to have those attitudes. $[\mathrm{O}(\mathrm{BO} \Phi \rightarrow \Phi)]$

I argue that the right solution is to give up the Enkratic Principle, viewing attitudinal coherence not as a requirement of rationality but instead as defeasible indication of epistemic blamelessness. I argue that this solution incurs the fewest theoretical costs of the available solutions.

It is worth briefly addressing a worry. One might wonder whether sacrificing one of the three claims really exhausts our options for solving the puzzle. One might be tempted to think that

\footnotetext{
${ }^{16}$ In other words, the requirements are 'indefeasible' - they remain binding in all possible situations. Darren Bradley ("Are There Indefeasible Epistemic Rules?" Philosophers' Imprint, 19 (2019)) and Jonathan Ichikawa \& Benjamin Jarvis, The Rules of Thought. (Oxford University Press, 2013)) endorse this view of requirements of rationality.

${ }^{17}$ I express Support in terms of evidence, but this is not necessary. One might think that non-evidential forms of rational support are also relevant to what one is rationally required to believe, and thus may wish to expand Support to include, for example, epistemic reasons to suspend belief, whether propositions are produced by a reliable method, or theoretical virtues such as simplicity or elegance. This would be compatible with the puzzle, and my proposed solution.
} 
we should deny the claim that rationality requires both the false higher-order belief and the conflicting first-order attitude. After all, if rationality does not require both then there is no conflict. For example, Lord and Sylvan argue that the required attitude at both the first- and higher-order is suspension ${ }^{18}$. However, this means giving up both Externalism and Support. In the cases at hand, the agent's evidence supports the false belief that rationality requires believing P. However, due to some other true rational requirement, rationality in fact requires something else that is incompatible with the false view (e.g. not believing P). Responding to this conflict by saying that, in fact, rationality requires neither of these apparently conflicting attitudes, but suspension instead, would mean denying both Support (rationality does not, in this case, require believing what one's total evidence supports), and Externalism (in this case, one is not required to believe what the true requirements require). This strategy is unnecessarily costly - it involves giving up two of the three claims, but we need only give up one. The strategies I explore involve giving up only one of the claims.

In the following section, I argue that we can diagnose the apparent conflict in Puzzle of Inconsistent Requirements as a conflation between two kinds of evaluation - requirement and appraisal. Distinguishing these evaluations means that we need not think that all three of the claims (Externalism, Support, Enkratic Principle) are associated with the same evaluation whether requirement or appraisal. This gives us a way to solve the puzzle, provided we can associate at least one claim with the evaluation of appraisal, rather than requirement. I argue that the Enkratic Principle is naturally conceived of as a principle of appraisal. This allows us to both preserve the requirement to believe what our total evidence supports and any other requirement of rationality we like (bar the Enkratic Principle) as fully robust requirements that apply without exception. Even better, the traditional motivations for thinking of the Enkratic

\footnotetext{
${ }^{18}$ Errol Lord and Kurt Sylvan, "Suspension, Higher-Order Evidence, and Defeat", forthcoming in Mona Simion and Jessica Brown (eds.), Reasons, Justification, and Defeat. Oxford University Press.
} 
Principle as a requirement of rationality can be accommodated by a view that takes it compliance with it as defeasible indication of epistemic blamelessness.

\section{Two Kinds of Evaluation}

This section diagnoses the apparent conflict in the Puzzle of Inconsistent Requirements as the conflation of two kinds of evaluation: requirement and appraisal. Distinguishing these permits a solution to the puzzle.

Judgments of epistemic rationality may involve either or both of the following claims:

Requirement: $\mathrm{S}$ has the attitudes required by the requirements of rationality.

Appraisal: $\mathrm{S}$ is epistemically blameless.

When an evaluation of rationality is a claim about requirement, it focuses on whether the agent has the attitudes she is required to have. Agents are evaluated as having met the requirements of rationality when they have the attitudes required by rationality. When an evaluation of rationality is a claim about appraisal, it focuses on whether and to what extent the agent deserves epistemic praise or blame. Agents are evaluated as epistemically blameless when they do not deserve epistemic blame, or they deserve epistemic praise. Various considerations can contribute to an agent's being epistemically blameless. For example, that she exhibits epistemic virtues or avoids epistemic vices ${ }^{19}$, that she responds appropriately given her epistemic perspective ${ }^{20}$, that she demonstrates the right kind of concern for epistemic reasons ${ }^{21}$, or that

\footnotetext{
${ }^{19}$ Quassim Cassam, "Vice Epistemology", The Monist 99 (2016); Vices of the Mind: from the Intellectual to the Political. (Oxford University Press, 2019).

${ }^{20}$ Jonathan Kvanvig, Rationality and Reflection: How to Think About What to Think. (Oxford University Press, 2014); Errol Lord, The Importance of Being Rational. (Oxford University Press, 2018); Michael Zimmerman, Living with Uncertainty: The Moral Significance of Ignorance. (Cambridge University Press, 2008).

${ }^{21}$ Cameron Boult, "Excuses, Exemptions, and Derivative Norms", Ratio 32 (2019).
} 
she manifests success-conducive dispositions ${ }^{22}$. Additionally various excuses, when applicable, can mitigate epistemic blame she might otherwise deserve - for example, that she was misled, deceived, did as well as she could given her circumstances, or lacked the relevant capacity $^{23}$. Importantly, evaluations of appraisal and requirement can come apart - agents should not always be praised (or escape blame) for doing what is required, and they do not always deserve blame for failing to do what is required. The distinction between evaluations of requirement and appraisal is well-established in ethics. For example:

\author{
Kant's Prudent Shopkeeper ${ }^{24}$. A shopkeeper prices his wares fairly, as \\ morality requires him to do. However, he does this not out of a motivation to \\ do what is fair, kind, or morally right, but out of a motivation to maximise \\ his profits. He knows that if he does not price his wares fairly, his customers \\ will go elsewhere. If he could make more profit by pricing his wares unfairly, \\ then he would do this instead.
}

Kant's shopkeeper does what is required - he succeeds in complying with the requirements, but he does so in such a way that does not deserve praise. So, he deserves a positive evaluation

\footnotetext{
${ }^{22}$ Maria Lasonen-Aarnio, "Enkrasia or Evidentialism?”; Timothy Williamson, “Justifications, Excuses, and Sceptical Scenarios", forthcoming in Julien Dutant \& Fabian Dorsch (eds.), The New Evil Demon Problem Oxford University Press.

${ }^{23}$ One might think that lacking capacities constitutes an exemption, rather than an excuse, although there is debate to be had over whether exemption is a sui generis category, or merely a full excuse. Nothing here turns on whether there is a distinction between excuse and exemption. For further discussion of the conditions for blameworthy belief see Pamela Hieronymi, "Responsibility for Believing", Synthese 161 (2008); Miriam McCormick, "Taking Control of Belief", Philosophical Explorations 14 (2011); Conor McHugh, "Epistemic Responsibility and Doxastic Agency", Philosophical Issues, 23 (2013); Nikolaj Nottelmann, Blameworthy Belief: A Study in Epistemic Deontologism. (Springer, 2007); Rik Peels, Responsible Belief: A Theory in Ethics and Epistemology. (Oxford University Press, 2016); Angela Smith, "Responsibility for Attitudes: Activity and Passivity in Mental Life", Ethics 115 (2005). For discussion of the practice of epistemic blaming, see Jessica Brown "What is Epistemic Blame?", Noûs 54 (2018).

${ }^{24}$ For a discussion of Kant's own example, see Jens Timmerman, "Acting from Duty: Inclination, Reason and Moral Worth" in Kant's "Groundwork of the Metaphysics of Morals": A Critical Guide ed. Jens Timmerman (Cambridge University Press, 2007).
} 
of requirement, and a neutral evaluation of appraisal ${ }^{25}$. Likewise, failing to meet requirements does not always deserve blame:

Toes. I step on your toe in a crowded lift, and in doing so cause you pain.

Suppose that, ceteris paribus, causing others pain for no good reason is prohibited by the requirements of morality. However, I step on your toe not out of any intention to cause you pain, but because the lift is crowded and I am not aware of where your toe is. Had I known your toe was there, I would not have stepped on it.

Here, I fail to comply with the requirement to avoid causing pain to others, but I do not deserve blame $^{26}$. In ethics, considerations relevant to agent appraisal are usually distinguished from considerations of whether the agent does what is required, and making this distinction is also useful in epistemology 27.

Consider the students of Logic 101. If they believe the contradiction, then they violate the requirements of rationality. However, various considerations suggest that they would nevertheless be epistemically blameless for doing so. For example, their forbidden first-order attitude (believing the contradiction) is a result of usually successful epistemic practices, such as trusting the testimony of an apparent expert and believing the conclusions of convincing arguments. We might think that they manifest praiseworthy epistemic virtues when they follow

\footnotetext{
25 This does not imply that he deserves blame. Other examples are possible in which the agent does what is required, but deserves blame. For example, a politician who makes a large donation to charity only to detract attention from his seriously corrupt activities. Positive evaluations of requirement do not imply positive evaluations of appraisal.

${ }^{26}$ Again, it does not necessarily deserve praise. I may deserve a neutral evaluation, or an excuse.

${ }^{27}$ Various others distinguish appraisal and requirement in both ethics and epistemology. For applications of the distinction in ethics, see Nomy Arpaly, Unprincipled Virtue: An Inquiry into Moral Agency (Oxford University Press, 2002) and Peter Graham, "In Defense of Objectivism About Moral Obligation”, Ethics 121 (2010). For applications of the distinction to epistemology, see John Hawthorne and Amia Srinivasan, "Disagreement Without Transparency: Some Bleak Thoughts" in The Epistemology of Disagreement. (Oxford University Press, 2013); Maria Lasonen-Aarnio, "Enkrasia or Evidentialism?", "Unreasonable Knowledge", Philosophical Perspectives 24 (2010); Clayton Littlejohn, Justification and the Truth-Connection. (Cambridge University Press, 2012); Jonathan Sutton, "Stick to what you know", Noûs 39 (2005), Without Justification. (MIT Press, 2007); Timothy Williamson, "Justifications, Excuses, and Sceptical Scenarios".
} 
their evidence where it leads (even when that destination is highly counter-intuitive), and when they take seriously their own higher-order judgments. Were they instead to not believe the contradiction, we might think that this would manifest epistemic vice - stubbornness, or closemindedness - and perhaps a lack of respect for the evidence and their own epistemic commitments $^{28}$. They can also appeal to excuses for violating the requirements. For instance, they have been misled by good, but unsound, arguments. They are philosophical novices, and have limited capacities to work out what is wrong with the arguments they are given. These considerations suggest that students in Logic 101 who come to believe the contradiction are epistemically blameless, despite violating a requirement of rationality.

Some have denied the distinction between the evaluations of requirement and appraisal, implying that evaluations that the agent is epistemically blameless and evaluations that the agent has met the requirements of rationality are one and the same ${ }^{29}$. However, anti-luminosity considerations offer an important reason to distinguish requirement and appraisal in epistemic rationality. Anti-luminosity says that there is no non-trivial condition for which it is always possible to know whether or not one has met that condition ${ }^{30}$. If this is right, then it will not always be possible to know when one has met the requirements of rationality. Logic 101 and Disagreement are examples of how one can fail to be in a position to know whether one has met the requirements. Failure to know what is required means that complying with what is required is not always under one's control, because we cannot always tell what we ought to do

\footnotetext{
${ }^{28}$ This is true even if we have prima facie justification for the basic laws of logic, as some have argued (Ichikawa \& Jarvis, The Rules of Thought; Titelbaum, "Rationality's Fixed Point (Or: In Defense of Right Reason)"; and Crispin Wright "Intuition, Entitlement and the Epistemology of Logical Laws", Dialectica 58 (2004)). In Logic 101 , the students are exposed to counter-arguments that they are not able to rationally reject, so it would be epistemically vicious for them to make use of this justification.

${ }^{29}$ See Kvanvig, Rationality and Reflection: How to Think About What to Think; Lord, The Importance of Being Rational; Ralph Wedgwood, The Value of Rationality. (Oxford University Press, 2017).

${ }^{30}$ Trivial conditions immune to anti-luminosity are those that hold in either all or no cases, and conditions for which one cannot change from being in a position to know that it obtains to not being in such a position (Timothy Williamson, Knowledge and its Limits. (Oxford University Press, 2002, 108)). See also Amia Srinivasan, "Are We Luminous?", Philosophy and Phenomenological Research 90 (2015); "Normativity without Cartesian Privilege", Philosophical Issues 25 (2015).
} 
in order to comply with the requirements ${ }^{31}$. In such cases, it is implausible that agents deserve epistemic blame for failing to meet requirements. Making meeting the requirements necessary for avoiding epistemic blame would mean that agents would sometimes deserve epistemic blame for failing to do what they were in no position to know they were failing to do. This would be implausibly harsh. To avoid this, many views of epistemic normativity recognise some blameless failures to meet requirements ${ }^{32}$, thus implicitly separating meeting requirements from epistemic appraisal.

It might have been thought that such harsh results could be avoided by adjusting what rationality requires so that the requirements of rationality are themselves luminous, and so can never be violated blamelessly. We might have them depend closely on the agent's mental states, or on how things seem to her by her own lights. However, this would not be sufficient. Anti-luminosity arguments show that no non-trivial condition is luminous, not even conditions for which compliance depends on how things seem from our own lights, such as feeling cold. Any genuinely luminous condition would need to be extremely trivial to ensure that agents were always in a position to know whether they were meeting $\mathrm{it}^{33}$, and requirements of rationality could not be this trivial ${ }^{34}$. The pressure to avoid both overly demanding and

\footnotetext{
${ }^{31}$ Srinivasan, "Normativity without Cartesian Privilege", 278.

${ }^{32}$ For example, those who endorse a truth or knowledge norm for belief typically respond to the New Evil Demon argument by evaluating envatted subjects who have false but responsibly formed beliefs as blameless. For discussion, see Brown, Fallibilism: Evidence and Knowledge; Stewart Cohen, "Justification and Truth". Philosophical Studies 46 (1984), Jeremy Fantl and Matthew McGrath, Knowledge in an Uncertain World (Oxford University Press, 2009), Christoph Kelp, "Justified Belief: Knowledge First-Style", Philosophy and Phenomenological Research 92 (2016), Clayton Littlejohn, "The Externalist's Demon" Canadian Journal of Philosophy 39 (2009), Sutton, Without Justification; Williamson, "Justifications, Excuses, and Sceptical Scenarios".

${ }^{33}$ Furthermore, it might be even more difficult for us to discern from the inside when we meet conditions that require us to be in particular mental states than when we meet external conditions (Eric Schwitzgebel, "The Unreliability of Naive Introspection", Philosophical Review 117 (2006); Srinivasan, "Normativity without Cartesian Privilege", 275.

${ }^{34}$ Even if such requirements were possible, they would need to be very different from traditional requirements of rationality. It is difficult to see how such a requirement could help adjudicate between competing consistent belief sets, or guide agents towards more rational belief sets (see Lasonen-Aarnio, "Unreasonable Knowledge").
} 
impossibly trivial requirements of rationality is a reason to distinguish requirement and appraisal.

\section{Solving the Puzzle of Inconsistent Requirements}

This section outlines how distinguishing requirement and appraisal allows us to solve the puzzle. Distinguishing evaluations of requirement and appraisal means that we need not think that agents in cases like Logic 101 and Disagreement are subject to inconsistent requirements. Instead, when agents have misleading evidence for false beliefs about what rationality requires, we can distinguish the question of which epistemic attitudes are rationally required from the question of whether the agent deserves epistemic blame for adopting those attitudes. Since these distinct evaluations are determined by different kinds of considerations, it will sometimes be possible for agents to blamelessly adopt attitudes prohibited by rationality, and vice versa. This allows us to explain why agents who have misleading evidence for false beliefs about what rationality requires seem to be subject to conflicting requirements of rationality - these apparent requirements reflect the distinct claims that can be involved in evaluations of rationality. So, when rationality prohibits believing $\langle\mathrm{P}\rangle$, agents would be irrational in the sense of failing to meet the requirements of rationality were they to believe $\langle\mathrm{P}\rangle$. However, depending on the circumstances, they might also be rational in the sense of being epistemically blameless, if their belief $\langle\mathrm{P}\rangle$ is held blamelessly.

Distinguishing these evaluations means that our three claims (Externalism, Support, Enkratic Principle) need not conflict. In the following section I argue that the Enkratic Principle can be associated with appraisal rather than requirement with minimal theoretical cost. This would mean that rationality requires, in all cases, that agents believe what their total evidence supports, and that they refrain from adopting any rationally prohibited attitudes. When agents 
have misleading evidence that rationality requires not believing $\langle\mathrm{P}\rangle$, when it in fact requires believing $\langle\mathrm{P}\rangle$, rationality requires the following beliefs:

$<\mathrm{I}$ am rationally required to not believe $\mathrm{P}>$

$<\mathrm{P}>$

However, agents in such circumstances may be epistemically blameless if they refrain from believing $\langle\mathrm{P}\rangle$, provided they do so in an epistemically blameless way. Equally, in not believing $\langle\mathrm{P}\rangle$, they would be failing to meet the requirement to believe $\langle\mathrm{P}\rangle$. By distinguishing requirement from appraisal, we need not also think that they deserve blame for this failure.

At this point, one might wonder whether the proposed cure is worse than the disease. The problem that we are attempting to solve is that given a plausible set of commitments, and the possibility of misleading evidence about what rationality requires, rationality issues inconsistent requirements: for some $\mathrm{P}$, it requires agents to both believe and not believe $\mathrm{P}$. If we give up the Enkratic Principle, agents are never subject to inconsistent requirements but they are sometimes required to be level-incoherent. One might wonder if this is any better. However, although neither situation is ideal, there are reasons to think that inconsistent requirements of rationality are worse than requirements to be level-incoherent.

Firstly, it is impossible to both (fully) believe and not believe P. So, the inconsistent requirements are impossible to fulfil. Although some have thought that level-incoherent belief is impossible, but this is less clear ${ }^{35}$. Of course, provided we remain neutral on whether the Ought of rationality implies Can, rationality may sometimes require the impossible. However,

\footnotetext{
35 At least some have thought it both possible and rational (Lasonen-Aarnio "Enkrasia or Evidentialism?", "Higher-order Evidence and the Limits of Defeat"; Weatherson, Normative Externalism). For arguments that it is impossible, see (see Jonathan Adler, “Akratic Believing?”, Philosophical Studies 110 (2002), Daniel Greco, "A Puzzle about Epistemic Akrasia" Philosophical Studies 167 (2014), David Owens "Epistemic Akrasia" The Monist 85 (2002), Philip Pettit and Michael Smith. "Freedom in Belief and Desire", Journal of Philosophy 93 (1996), 448.
} 
whatever we think about this, inconsistent requirements are not only a problem for the agent subject to them. If rationality generates inconsistent requirements then rationality itself contains logical contradictions. This is a problem - contradictions entail triviality, at least assuming Standard Deontic Logic. Here is the derivation ${ }^{36}$ :

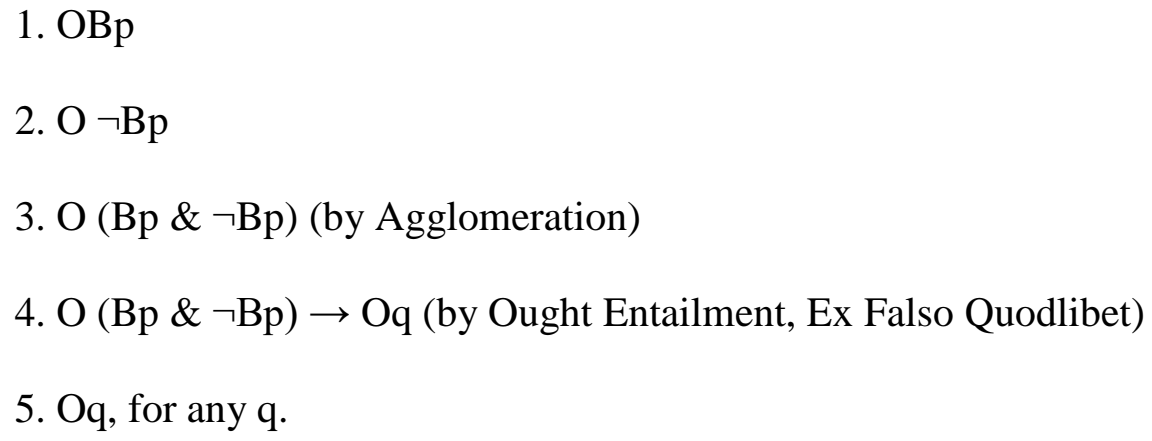

From inconsistent requirements ((1) and (2)), we can derive anything and everything as a rational requirement. A theory that permits this is unacceptably trivial. Of course, we could reject Standard Deontic Logic ${ }^{37}$. While some have taken this option ${ }^{38}$, it is unnecessary to solve the puzzle, and sufficiently drastic that we have reason to seek others. A theory that gives up the Enkratic Principle offers recommendations for the agent that are no worse than inconsistent requirements, and it is significantly better for theoretical consistency. Not only this, but as the following section argues, it is the least theoretically costly of the available solutions and it can accommodate the usual motivations for the Enkratic Principle.

\footnotetext{
${ }^{36}$ Ought Entailment: Necessarily $((\mathrm{p} \rightarrow \mathrm{q}) \rightarrow(\mathrm{Op} \rightarrow \mathrm{Oq})) ;$ Agglomeration: Op \& Oq $\rightarrow \mathrm{O}(\mathrm{p} \&$ q); Ex Falso Quodlibet: $(\mathrm{p} \& \neg \mathrm{p}) \rightarrow \mathrm{q}$.

${ }^{37}$ Indeed, some have thought there are independent reasons to do this. See (Pigozzi et al. (2007); Sayre-McCord (1986)). I have no quarrel with these arguments, since nothing I say here depends on the truth of SDL. Rather, my point is that the puzzle itself is not a reason to give up SDL.

${ }^{38}$ For example, David Alexander, "The Problem of Respecting Higher-Order Doubt", Philosophers' Imprint, 13 (2013), Christensen. "Higher-Order Evidence", and Nicholas Hughes, "Dilemmic Epistemology", Synthese 196 (2019) propose thinking of cases such as Logic 101 and Disagreement as epistemic dilemmas. Not only does this involve an unnecessary rejection of SDL, it is less a solution to the puzzle than a way of saying that the puzzle does not require a solution.
} 


\section{Giving Up the Enkratic Principle}

This section defends the strategy of solving the Puzzle of Inconsistent Requirements by giving up the Enkratic Principle. First, this solution to the puzzle is the least theoretically costly option (§5.1), and, second, the main motivations for thinking of attitudinal coherence as a requirement of rationality are equally well, if not better, accommodated by a view that associates it with appraisal (\$5.2).

\subsection{A Comparative Bargain}

First, giving up the Enkratic Principle is the least theoretically costly option. One might worry that it would be better to give up one of the other claims - Externalism or Support - than the Enkratic Principle. This subsection addresses this worry, arguing that while the puzzle could be solved by giving up any of the three claims, rejecting Externalism or Support involves significant theoretical $\operatorname{costs}^{39}$. Giving up the Enkratic Principle is a comparative bargain.

First, the costs of giving up Externalism. According to Externalism, the requirements hold independently of what the agents subject to them believe, what evidence they have, what they are in a position to know, and all other features of the agents' epistemic perspectives. So, if rationality requires you to refrain from believing contradictions, then it requires you to refrain from believing contradictions regardless of whether you believe that you are required to refrain from believing contradictions. Rejecting Externalism would mean denying this, and holding instead that what rationality requires depends on your perspective, such as how things appear to you, what you already believe, and the evidence you have available ${ }^{40}$. There are significant costs to accepting such a view.

\footnotetext{
${ }^{39}$ As previously mentioned, giving up more than one would involve even greater theoretical cost (the sum of the costs involved in giving up each of the individual claims).

${ }^{40}$ See Hartry Field, "Epistemology without Metaphysics", Philosophical Studies 143 (2009); John Gibbons, The Norm of Belief. (Oxford University Press, 2013); Lord, The Importance of Being Rational; Kolodny, " Why Be Rational?"; Kiesewetter (2011); Benjamin Kiesewetter, The Normativity of Rationality. (Oxford University Press,
} 
First, denying Externalism implies that any attitude at all could, in principle, count as rational, provided that one has sufficient perspectival support for it. This is a problem because it makes the epistemic value of rationality mysterious, particularly for agents who already have many false beliefs. If being rational is merely a matter of making sense from your own perspective, there is no reason to think that being rational will lead you to valuable epistemic goods such as truth and knowledge ${ }^{41}$. It may even exasperate the epistemically negative consequences of false belief by further isolating us from epistemic goods ${ }^{42}$.

Second, rejecting Externalism would mean endorsing an error theory about traditional requirements, such that a statement of what rationality requires would be impossible to make in advance of considering the agent's precise situation. This would, surprisingly, turn cases of misleading evidence about what rationality requires into counterexamples to particular putative requirements of rationality. This would constitute a significant revision to how we ordinarily think of rational requirements ${ }^{43}$.

Third, rejecting Externalism would prevent epistemic rationality from guiding agents towards epistemically better belief sets. If we think that rationality depends entirely on how things seem from one's perspective then no particular requirement of rationality will be genuinely binding for all agents. One unwelcome consequence of this is that requirements of rationality

2017); Kvanvig, Rationality and Reflection: How to Think About What to Think; Joseph Raz, "The Myth of Instrumental Rationality", Journal of Ethics and Social Philosophy 1; Daniel Whiting, "Keep Things in Perspective: Reasons, Rationality, and the A Priori", Journal of Ethics and Social Philosophy 8 (2014); Jonathan Way and Daniel Whiting, "Perspectivism and the Argument from Guidance", Ethical Theory and Moral Practice 20 (2017); Zimmerman, Living with Uncertainty: The Moral Significance of Ignorance.

41 This mysteriousness invites the question of whether one should be rational, a question that has been well explored, without clear resolution, for the case of practical rationality (Broome, Rationality Through Reasoning; Kolodny, "Why Be Rational?"; Raz, "The Myth of Instrumental Rationality". It thus may be considered an advantage if our solution precludes this question for epistemic rationality.

${ }^{42}$ This is a version of a familiar objection to coherentist theories of justification. Entirely false belief sets could count as justified if all that is required for justification is coherence (see Ernest Sosa, "The Raft and the Pyramid: Coherence versus Foundations in the Theory of Knowledge", Midwest Studies in Philosophy 5 (1980), 19, and particularly worrying in light of the observation that those who believe conspiracy theories often have beliefs that are largely consistent and well-supported from their perspective (see C. Thi Nguyen, "Echo Chambers and Epistemic Bubbles", Episteme 17 (2020), "Cognitive Islands and Runaway Echo Chambers: Problems for Epistemic Dependence on Experts", Synthese 197 (2018)).

${ }^{43}$ See Lasonen-Aarnio, "Higher-Order Evidence and the Limits of Defeat", 332 on this point. 
cannot provide information about which epistemic attitudes are rational, and so cannot be used by agents to guide their epistemic activities.

Similarly serious theoretical costs come with giving up Support. Various otherwise distinct accounts of epistemic rationality retain a commitment to $i^{44}$ - giving it up would be a radical overhaul for which we would need a very good reason. Moreover, while some have taken this option, their key motivation has typically been to preserve the Enkratic Principle. ${ }^{45}$ For this move to be plausible, we would require independent reason to think that the Enkratic Principle expresses a more important aspect of epistemic rationality than Support. This independent reason has not been forthcoming. Furthermore, as the following subsection notes, others have motivated the Enkratic Principle by appeal to evidentialist principles related to Support ${ }^{46}$, suggesting that Support in fact has theoretical primacy.

So, there are significant theoretical costs to solving the puzzle by giving up either Externalism or Support. If there are comparatively minimal costs involved in giving up the Enkratic Principle, this would be a reason to prefer giving it up. The following subsection argues that the costs involved are indeed minimal, since the traditional motivations for thinking that the Enkratic Principle is a requirement of rationality can be accommodated by a view that thinks of it as associated with evaluations of appraisal.

\subsection{Accommodating Traditional Motivations}

\footnotetext{
${ }^{44}$ See, amongst many others, Richard Feldman and Earl Conee, "Evidentialism", Philosophical Studies, 48 (1985); c; Michael Huemer, "Does Probability Theory Refute Coherentism?", Journal of Philosophy 108 (2011); James Joyce, "Accuracy and Coherence: Prospects for an Alethic Epistemology of Partial Belief" in Franz Huber and Christoph Schmidt-Petri (eds.), Degrees of Belief (Synthese, 2009); Thomas Kelly, "The Rationality of Belief and Other Propositional Attitudes", Philosophical Studies 110 (2002); Lasonen-Aarnio, "Higher-Order Evidence and the Limits of Defeat"; Declan Smithies, "Moore's Paradox and the Accessibility of Justification", Philosophy and Phenomenological Research 85 (2012); Williamson, Knowledge and its Limits; Weatherson, Normative Externalism.

${ }^{45}$ Lasonen-Aarnio, "Enkrasia of Evidentialism?"; Littlejohn, "Stop Making Sense? On a Puzzle about Rationality.

${ }^{46}$ For example, Worsnip, "The Conflict of Evidence and Coherence".
} 
This subsection shows how traditional motivations for thinking that the Enkratic Principle is a requirement of rationality can be accommodated by a view that takes compliance with the principle to be defeasibly indicative of epistemic blamelessness.

Perhaps the most obvious such motivation is the idea that rationality demands attitudinal coherence, including the kind of inter-level coherence prohibited by the Enkratic Principle. In favour of this idea, it is tempting to appeal to the Moorean quality of belief combinations such as:

\section{$<\mathrm{P}$, but I ought not believe that $\mathrm{P}\rangle$}

These are prohibited by the Enkratic Principle, and their prima facie irrationality may seem to suggest that the Enkratic Principle is a requirement of rationality ${ }^{47}$, or that level-incoherent belief could only be rational for fragmented minds ${ }^{48}$. Some have been so confident that the Enkratic Principle expresses a genuine requirement of rationality that they have relied on to argue for far more controversial conclusions ${ }^{49}$. However, the intuition these claims rely on is insufficiently fine-grained to establish that the Enkratic Principle is a requirement of rationality. We cannot be sure of what it tracks - compliance with rational requirements, or some nonnegative epistemic status, such as blamelessness ${ }^{50}$.

Another motivation for thinking that the Enkratic Principle is a requirement of rationality is the idea that it follows from an independent commitment to evidentialism, because one's total evidence could never support level-incoherent belief combinations. In this vein, Davidson

\footnotetext{
${ }^{47}$ See Smithies, "Moore's Paradox and the Accessibility of Justification".

${ }^{48}$ See Greco, "A Puzzle about Epistemic Akrasia", and Donald Davidson "Deception and Division" in Problems of Rationality. (Oxford University Press, 2004).

${ }^{49}$ See Littlejohn's argument against Evidentialism ("Stop Making Sense? On a Puzzle about Rationality"), and Titelbaum's argument for the impossibility of rational mistakes about rationality ("Rationality's Fixed Point (Or: In Defense of Right Reason").

${ }^{50}$ A similar point is often made about intuitions of justification and blamelessness (see Clayton Littlejohn, "A Plea for Epistemic Excuses" forthcoming in Julien Dutant \& Fabian Dorsch (eds.), The New Evil Demon Problem (Oxford University Press); Sutton, Without Justification; Williamson, "Justifications, Excuses, and Sceptical Scenarios", “Ambiguous Rationality”, Episteme 14 (2017).
} 
suggests that epistemic akrasia - a kind of level-incoherence - manifests the epistemic "sin" of failing to believe what one's total evidence supports ${ }^{51}$. However, while it may be true that in most cases, when the evidence supports $<\mathrm{P}>$ it does not also support $<$ I ought not believe $\mathrm{P}>$, there appear to be rare, but not impossible, exceptions. For example, when evidence is misleading about itself, the evidence would appear to support level-incoherent states. Typical examples are cases in which agents have good evidence for $\mathrm{P}$, but misleading evidence about their abilities to assess the evidence for P effectively (see Medicine, above). In such cases, your evidence appears to support both $\langle\mathrm{P}\rangle$ and $\langle$ my evidence does not support $\mathrm{P}\rangle$. So, a commitment to evidentialism does not show that the Enkratic Principle is a requirement of rationality, although the rarity of such cases might show that it is usually good epistemic practice to avoid level-incoherent combinations, since they are usually not supported by one's total evidence. This is, however, compatible with the view that compliance with the Enkratic Principle is defeasible indication of blamelessness.

Another traditional motivation for thinking that the Enkratic Principle is a requirement of rationality is appeal to the idea that rationality requires good belief management, and good belief management requires compliance with the Enkratic Principle. For example, one might think that even if one's total evidence can sometimes support level-incoherent beliefs ${ }^{52}$, violating the Enkratic Principle could never be rational because rationality exerts normative pressure on us to revise our beliefs in response to our own beliefs about what we ought to believe $^{53}$. Perhaps this is because doing so involves misusing one's higher-order beliefs ${ }^{54}$,

\footnotetext{
${ }^{51}$ Davidson, "Deception and Division", 201.

${ }^{52}$ Some have argued that it cannot, because the levels cannot be separated so easily $-\langle\mathrm{P}\rangle$ is itself evidence for $<\mathrm{I}$ ought to believe that $\mathrm{P}>$. For reasons to resist this view, and adopt a partially level-incoherent position (see Sliwa and Horowitz, "Respecting All the Evidence").

${ }^{53}$ For example, Kvanvig (Rationality and Reflection: How to Think About What to Think) sees this feature of the "egocentric predicament" as a central concern of epistemic rationality. This leads him to endorse a highly perspectivist account of rational requirement, which I have argued here comes with serious costs.

${ }^{54}$ David Christensen "Higher-Order Evidence"; "Rational Reflection”, Philosophical Perspectives 24 (2010); "Disagreement as Evidence: The Epistemology of Controversy", Philosophy Compass 45 (2009); Littlejohn, "Stop Making Sense? On a Puzzle about Rationality".
} 
failing to take seriously one's "conspicuous reasons" $" 55$, failing to reason appropriately from one's beliefs ${ }^{56}$, or failing to respect one's evidence by taking one's own judgments about what it supports seriously ${ }^{57}$.

However, complying with the Enkratic Principle is not always an example of good epistemic conduct. Complying with the Enkratic Principle only usually coincides with good epistemic conduct. Again, this is entirely compatible with thinking of the Enkratic Principle as a principle of appraisal, rather than requirement. Compare two possible students who take Logic 101. The first, call her Lazy, does not pay much attention in class or do the homework exercises. She exerts minimal intellectual effort, ignoring the arguments and testimony she receives in class, and would have nothing to say in response to them. When she does consider what rationality requires of her with respect to believing contradictions, she finds the idea that rationality could ever require her to believe contradictions "silly", and so refuses to believe it ${ }^{58}$. Although her beliefs are true and comply with the Enkratic Principle, this is not an example of good epistemic conduct. In reasoning "upstream" 59 she disregards her evidence, and she does for insufficent reason (that she thinks the view is "silly" ${ }^{60}$ ). In this case the agent complies, but is not epistemically blameless.

Not only is Lazy not manifesting good epistemic conduct, she is doing significantly worse, epistemically, than other possible students who do comply with the Enkratic Principle. A second student, call her Diligent, considers what her teacher says and the arguments studied in

\footnotetext{
${ }^{55}$ Lasonen-Aarnio, “Enkrasia or Evidentialism?”.

${ }^{56}$ Horowitz, "Epistemic Akrasia".

${ }^{57}$ Worsnip, "The Conflict of Evidence and Coherence".

58 Compare cases of reliable clairvoyants (see Bonjour, The Structure of Empirical Knowledge (Harvard University Press, 1985) - Lazy gets it right, but does not have good reason to believe that she is getting it right.

${ }^{59}$ As Kolodny (“Why Be Rational?", 529) puts it. See also Schroeder's 'symmetry' objection to thinking of the practical Enkratic Principle as wide scope (Mark Schroeder, "The Scope of Instrumental Reason", Philosophical Perspectives 18 (2004), 339, which points out that only some of the ways one could bring oneself in line with the Enkratic Principle intuitively seem rational.

${ }^{60}$ While Lewis ("Letters to Priest and Beall") also responds to the arguments of dialetheism in this way, we can charitably assume that his philosophical experience means that he would more to say in response to the dialetheist's arguments.
} 
class. She sees how they lead to the conclusion that rationality sometimes requires contradictory belief, and so she believes this. However, when she tries to believe the contradiction itself, she finds this difficult ${ }^{61}-$ it seems so very counterintuitive. So, she has level-incoherent beliefs. However, she has arrived at these beliefs by managing her beliefs well. She believed the conclusion of a convincing argument, and she refrained from believing what seems counterintuitive. Perhaps she could have done better, but she has certainly managed her beliefs better than her fellow student, Lazy. Here, the agent is epistemically blameless despite not complying with the Enkratic Principle.

Not only this, but there are possible cases in which managing one's beliefs as well as one can means ending up with beliefs that violate the Enkratic Principle. Suppose that epistemologists in the future develop a device, call it the Excellent Evidence Evaluator, that can perfectly evaluate what one's evidence supports in any scenario. Everyone uses these devices and comes to depend on them. Your great-granddaughter has one of these devices, and her higher-order evidence suggests that her first-order evidence is misleading, when in fact it is not. In this case, her total evidence appears to support both $\langle\mathrm{P}\rangle$ and $\langle$ my evidence does not support $\mathrm{P}\rangle$. Believing what you believe to be supported by your evidence is an example of managing your beliefs well, so in trusting her Excellent Evidence Evaluator, your great-granddaughter is managing her beliefs well, and so is blamelessly violating the Enkratic Principle ${ }^{62}$.

Conformity to the Enkratic Principle is thus not necessary for good belief management. However, we can preserve the intuitive idea that good epistemic agents usually comply with the Enkratic Principle by understanding compliance as defeasible indication of epistemic

\footnotetext{
${ }^{61}$ Likely, if, as some have argued, contradictory belief is impossible (see David Lewis, "Logic for Equivocators", Noûs 16 (1982); Worsnip, "The Conflict of Evidence and Coherence").

62 This possibility is consistent with what some defenders of the orthodox view say. Horowitz, for example, argues that level-coherence is necessary for rational belief in the majority of cases, but concedes that there are some cases in which the higher- and first-order evidence support incompatible propositions, and rationality does not require level-coherence ("Epistemic Akrasia", 735-40). However, this position is not consistent with the view that the Enkratic Principle is a requirement of rationality, holding in all cases.
} 
blamelessness. Consideration of Lazy shows us that if compliance is such an indication, it must be defeasible. Consideration of Diligent and the Excellent Evidence Evaluator shows us that compliance with the Enkratic Principle is not necessary for epistemic blamelessness.

Finally, a key motivation for thinking that the Enkratic Principle is a requirement of rationality - one that is much better accommodated by the proposed solution than the orthodox view - is the idea that to be rational is to be epistemically blameless ${ }^{63}$. A tempting thought is that agents who comply with the Enkratic Principle are immune from epistemic blame - perhaps because maintaining level-coherence constitutes good epistemic conduct, manifests epistemic virtues, or is a reasonable thing to expect of rational agents. However, the cases of Diligent and the Excellent Evidence Evaluator show this to be not quite true. Compliance with the Enkratic Principle is only usually, not always, indicative of epistemic blamelessness. So, the grain of truth in this motivation is easily accommodated by a view that takes the Enkratic Principle to be indicative of epistemic blamelessness.

In sum, giving up the Enkratic Principle involves only minimal theoretical costs. This makes it a preferable solution to giving up either of the other two claims (Externalism and Support). The final section outlines the correct evaluation of agents in cases such as Logic 101 and Disagreement.

\section{Evaluating Misled Agents}

This section illustrates the evaluation of agents with misleading evidence about what rationality requires offered by the proposed solution. When agents have misleading evidence that rationality requires not believing $\mathrm{P}$, but in fact rationality requires believing $\mathrm{P}$, then rationality requires the following beliefs:

\footnotetext{
${ }^{63}$ See Kvanvig, Rationality and Reflection: How to Think About What to Think; Lord, The Importance of Being Rational; Wedgwood, The Value of Rationality.
} 
$<\mathrm{I}$ am rationally required to not believe $\mathrm{P}>$

$<\mathrm{P}>$

The agent's total evidence supports that rationality requires not believing $\mathrm{P}$, so she should believe this. Rationality also requires believing P, so she should believe P. However, she may be epistemically blameless is she does not believe $\mathrm{P}$, depending on how she conducts herself epistemically. The agent is required to have a combination of beliefs that violates the Enkratic Principle.

We avoid the possibility of rationality generating inconsistent requirements because the Enkratic Principle is not a requirement of rationality. If the agent does comply with the Enkratic Principle, this may indicate epistemic blamelessness, although we cannot be sure of this without knowing more about her and her situation.

I have argued that the best way to solve the Puzzle of Inconsistent Requirements is to distinguish evaluations of requirement and appraisal, and think of compliance with the Enkratic Principle not as a requirement of rationality, but rather defeasible indication that the agent is epistemically blameless. This solves the puzzle with minimal theoretical cost, while vindicating the motivations that have contributed to the orthodox view of the Enkratic Principle's status. ${ }^{64}$

\footnotetext{
${ }^{64}$ I am grateful to many people for reading early drafts of this paper and discussing these ideas with me. The following people deserve particular mention: Corine Besson, Jessica Brown, Philip Ebert, Davide Fassio, Nick Hughes, Maria Lasonen-Aarnio, Clayton Littlejohn, Justin Snedegar, Bernard Salow, Kurt Sylvan, Brian Weatherson, and Daniel Whiting. Earlier versions of this paper were presented at the 2018 Oxford Graduate Conference, the 2018 Joint Aristotelian Society/Mind Association Postgraduate Session, the 2015 Arché Epistemic Incoherence Workshop, the 2015 Edinburgh Graduate Conference, the Arché Epistemology Seminar, the St Andrews Friday Seminar, and the University of Michigan GSWG. I am also grateful to the European Research Council (Grant \#789270, "Roots of Responsibility"), and the Arts and Humanities Research Council (AH/T002638/1 "Varieties of Risk") for financial support while writing this paper.
} 